\title{
Cliometrica after 10 years: definition and principles of cliometric research
}

\author{
Claude Diebolt ${ }^{1}$
}

Published online: 24 September 2015

(C) Springer-Verlag Berlin Heidelberg 2015

"[...] cliometricians have been explaining to their colleagues in history the wonderful usefulness of economics. It is time they began explaining to their colleagues in economics the wonderful usefulness of history. [...] It is no accident that some of the best minds in economics value it highly. What a pity, then, that the rest have drifted away."

(D. McCloskey, “Does the Past Have Useful Economics?”Journal of Economic Literature, 1976, p. 455).

I define cliometrics as the quantitative projection of social sciences in the past. Cliometrics is, more precisely, the combination of causal explanations embedded in (economic) models, with or without counterfactual speculation, in order to screen the relative importance of various factors, i.e., of forces (in natural sciences) believed to have been operative in a given historical situation. Assessment of cliometrics can proceed only if the nature of causal explanation has been resolved. Is causation only correlation and causal analysis the search for the maximum of consistency of correlations? Or is causation observed correlations, explained in terms of forces or mechanisms at work assuring that similar causes must be followed by similar effects? In response to the cliometric research agenda, methodology (the study of methods) or the methods themselves employed by a science or a discipline (here in history and in economics) become central.

Over the last 10 years, Cliometrica, the journal of historical economics and econometric history, follows the cliometric ambition to understand and to explain the complexity of economic growth phenomena in two different but related fields, history and economics.

Claude Diebolt

cdiebolt@unistra.fr

1 Founder, Publication Director and Managing Editor of Cliometrica, Strasbourg, France 
Cliometrica's mission is:

- To avoid the development of economic history and measurement without economic theory. The journal displays also a clear line between applied economics and cliometrics. Cliometrics in Cliometrica is history, (economic) theory and statistics/econometrics.

- To introduce modern quantitative methods in social sciences. Cliometrics for history as experimental economics for today? Yes. Economic actors are not passive: game theory, analytic narratives. Cliometrics as pure mathematics? No. Cliometrics as physics? Yes. Linking economic theory with observed stylized facts or "laws" to understand and explain how a/the system worked. Cliometrics as biology? Yes. Evolutionary perspective. Cliometrics as political philosophy? Yes. Designing optimal institutions instead of describing the world. Culture and institutions do matter... history matters!

- To produce new statistical datasets, i.e., improving the quality and the controlling of the databases in the tradition of the national institutes of statistics.

- To use the counterfactual approach. First, to underscore the importance of a particular causal factor that was operative in the situation under consideration. If slavery had not existed in the USA, then the Civil War would not have been fought. Alternatively and through the concept of social savings, if railroads had not existed in the USA, then the gross national product in 1890 would have been less than it actually was. Second, to add (rather than to subtract) a particular causal factor and speculate about the impact which that mentally added factor might have had. What if Nazi Germany had won World War II?

- To discuss the multiplicity of erroneous representations in economic history (path dependence, myths, falsifications, etc.).

Cliometrica is concerned with the unique, but also with the average. The ultimate goal, or at least one of its ultimate goals, is to find the underlying regularities in the interaction of economic and social variables, of production and distribution through time.

Since 2007, the articles published in the journal are the result of the combination of "clio" (the muse of history) and "metrics" (the art of measurement). The procedures, concepts, mental rules, postulates, analytical techniques, personal beliefs, generalizations, etc., implemented in cliometric research became therefore central to the journal, also because axioms, postulates, premises, assumptions, and hypothesis were the starting points of most articles, in history to designate the general frame of reference in order to catch the complexity for a field of inquiry, in economics to designate the statements accepted as true without necessarily establishing their complete validity.

Defining the papers published in Cliometrica since 10 years is finally as simple as remembering again and again the analytical devices or principles now being employed in cliometrics at the international level. 
- Cliometric research is more and more embedded in economic models. The models in turn are combined (or not) with counterfactual speculation to assess the importance of various causal forces observed to operate in a particular historical setting.

- The importance of the production of new databases.

- Quantification, statistics and econometrics, may not bring everything to a certainty, but it can give to many historical debates a perspective that would otherwise be completely lacking.

Of course, these cliometric principles must face general difficulties:

- The imperfection of surviving data. Data must be built and treated carefully, with patience and humility. Like other fragments of surviving historical evidence, data are shot through with biases, mistaken judgments, and errors.

- The uncertain importance of non-operational causal factors. How to organize reality into homogeneous sets or entities? Only by abstraction, i.e., only by ignoring as relevant some of the characteristics of a specific event? Generalizations are incomplete. The reason is simple. All previous experimental situations may have included an unknown but relevant cause, and there is no way to prove that this was not the case. In other words, causal explanation consists of subsuming specific facts under generalization. If one of the causes of World War II was the series of treaties imposed at the end of World War I, does a complete explanation of World War II have to include the causes of war in 1914 and its end in 1918, the causes of those causes, and so on?

- The unknown degree of imperfection in any theoretical model resulting from its neglect of causal factors and its use of assumptions which distort reality.

Cliometrica encourages the methodological debate (not a sterile Methodenstreit), the use of economic theory, mathematical model building, and the reliance upon quantification to support analytical frameworks with historical data. Moreover, Cliometrica stresses the use of standard historical knowledge, wie es eigentlich gewesen ist, to suggest new avenues of research as well as the use of statistical theory and econometrics to combine models with data into a single consistent explanation. While the juxtaposition of cross-fertilization of new ideas-emanating from methodological innovations and from economic theory-form the core of cliometric research, Cliometrica aims to forge steps ahead to encourage researchers to devise ever new strategies to reconcile these along the dynamic path of history.

Since its official creation in June 2006 by contract signature in Strasbourg with the Springer Verlag, the main ambition of Cliometrica is (and remains) in continuity of Gustav Schmoller's German Historical School and of Lucien Febvre's and Marc Bloch's Annales School (both also created in Strasbourg, respectively, in 1870-1880 and in 1920-1930), and with the exceptional support of an international editorial board and of reviewers from all over the world, to close the gap between the Geisteswissenschaften and the Naturwissenschaften, i.e., to move from the historical verstehen or understanding side to the economic erklären or explaining side or, 
much better, mixing both approaches, facts and stylized facts, explaining the economic experience of the past and understanding the ways in which economic factors influence social and political developments, for an increased knowledge of the past, present, and future economic and social development of developed and developing economies, for the achievement of a unified approach of the social sciences.

The recent publication of the Handbook of Cliometrics $^{1}$ is another original illustration of the validity of this belief.

Happy Birthday to Cliometrica!

$\overline{1}$ Diebolt C., Haupert M. (Eds.): Handbook of Cliometrics, Springer, Berlin, 2016. 